\title{
Effect of adenoid hypertrophy on the upper airway and craniomaxillofacial region
}

\author{
Hongwei Wang', Xiaotong Qiao' ${ }^{2}$, Suqing $\mathrm{Qi}^{3}$, Xiaolan Zhang ${ }^{4}$, Song $\mathrm{Li}^{1}$ \\ ${ }^{1}$ Department of Orthodontics, Beijing Stomatological Hospital, Capital Medical University, Beijing, China; ${ }^{2}$ Department of Oral Medicine, College \\ of Stomatology, Hebei Medical University, Shijiazhuang, China; ${ }^{3}$ Department of Orthodontics, Eye Hospital of Hebei, Xingtai, China; ${ }^{4}$ Department \\ of Otolaryngology, Eye Hospital of Hebei, Xingtai, China \\ Contributions: (I) Conception and design: H Wang; (II) Administrative support: S Li; (III) Provision of study materials or patients: X Zhang; (IV) \\ Collection and assembly of data: X Qiao; (V) Data analysis and interpretation: S Qi; (VI) Manuscript writing: All authors; (VII) Final approval of \\ manuscript: All authors. \\ Correspondence to: Song Li. Department of Orthodontics, Beijing Stomatological Hospital, Capital Medical University, Beijing 100853 , China. \\ Email: dentistli@263.net.
}

Background: In recent years, annual incidences of adenoid hypertrophy (AH), a highly common tissue lesion in children, have increased. Currently, research on $\mathrm{AH}$ has focused on its obstruction of nasal cavity function, and little has been written on its influence on the upper airway's bone structure. For this reason, our present study seeks to determine the influence of $\mathrm{AH}$ on both the morphological development characteristics of the upper airway and the craniofacial features in children, with the goal being to offer more choices for diagnosing and treating the condition in the future.

Methods: From June 2019 to December 2020 in Department of Orthodontics, Beijing Stomatological Hospital, Capital Medical University, 38 children with AH admitted to the Department of Otolaryngology [research group (RG)] and 35 children [control group (CG)] who underwent orthodontic treatment over the same time span were selected as the research objects. X-ray examination of the lateral position of the head, observation of the maxillofacial structure, and detection of the children's height, growth factors, and sleep status, and analysis of the differences between the two groups.

Results: The height of RG, insulin-like growth factor-1 (IGF-1) as well as insulin-like growth factor binding protein-3 (IGFBP-3) were all lower than CG $(\mathrm{P}<0.05)$, the upper airway became narrower, and the malocclusion was aggravated $(\mathrm{P}<0.05)$. Cephalometric measurement showed that the angle between the subspinale and sella at nasion (SNA angle) and the angle between the subspinale and supraemental at nasion (ANB angle) of RG children decreased, and the angle between the supraemental and sella at nasion ( $\mathrm{SNB}$ angle) increased $(\mathrm{P}<0.05)$. In addition, the sleep quality of $\mathrm{RG}$ was significantly lower than that of $\mathrm{CG}$ $(\mathrm{P}<0.05)$.

Conclusions: AH can change a child's breathing mode and function by giving rise to upper airway stenosis, and by inducing deformities of their craniomaxillofacial region and oral cavity, thus disrupting their normal growth and development.

Keywords: Adenoid hypertrophy (AH); upper airway; craniomaxillofacial region; growth and development

Submitted Aug 19, 2021. Accepted for publication Oct 16, 2021.

doi: $10.21037 /$ tp-21-437

View this article at: https://dx.doi.org/10.21037/tp-21-437 


\section{Introduction}

Adenoid hypertrophy (AH) is a highly common tissue lesion in children and is mainly related to nasopharyngitis (1). According to statistics, worldwide there are over 600,000 new cases of $\mathrm{AH}$ each year, and the trend is increasing annually (2). AH mainly causes a series of uncomfortable and inflammatory changes in the ear, nose, and throat. However, it can also lead to deformities in the development of the craniomaxillofacial region as it forces patients to engage in long-term open mouth breathing (3). In addition, AH also greatly impacts eating, so for younger patients it may also compromise their intake of nutrients and thus disrupt their growth and development (4). At this stage, the examination and diagnosis of $\mathrm{AH}$ is still complicated, and nasal endoscope, nasopharynx palpation, and X-ray are all required to confirm $\mathrm{AH}$ (5). In clinical practice, resection is recommended for the treatment of $\mathrm{AH}$ as it is the most effective treatment (6). However, for children whose body function is not fully developed, an operation will bring about serious post-operative traumatic stress and require a long rehabilitation cycle (7). Therefore, a deeper understanding of the pathogenic mechanism and influence of $\mathrm{AH}$ is key to finding a new and effective diagnosis and treatment plan for the condition.

Thus far, research on $\mathrm{AH}$ has focused on its obstruction of nasal cavity function $(8,9)$, while little has been written on its influence on the upper airway's bone structure. As we all know, adenoid facies is the most common complication of $\mathrm{AH}$, and is caused by $\mathrm{AH}$ hindering the function of the nasal respiratory tract (10). Moreover, an earlier study has found that tracheitis and respiratory tract infection are also potentially bound up with the structural changes of the upper airway in children (11). Understanding how AH alters the upper airway may be the key to finding a new diagnosis and treatment plan for AH. For this reason, our study sought to determine the influence of $\mathrm{AH}$ on both the morphological development characteristics of the upper airway and the craniofacial features in children, with the goal being to offer more choices for diagnosing and treating the condition in the future. We present the following article in accordance with the STROBE reporting checklist (available at https://dx.doi.org/10.21037/tp-21-437).

\section{Methods}

\section{Research participants}

In total, 73 children who were admitted to the Department of Orthodontics, Beijing Stomatological Hospital, Capital Medical University between June 2019 and December 2020 were enrolled in the study. Thirty-eight of these children had $\mathrm{AH}$ and were included in our research group (RG), while 35 underwent orthodontic treatment and were included in the control group (CG). The study was conducted in accordance with the Declaration of Helsinki (as revised in 2013). This experiment was carried out with permission from the Ethics Committee of Beijing Stomatological Hospital, Capital Medical University, and informed consent forms were signed by the guardians of all enrolled children.

\section{Inclusion and exclusion criteria}

Children were included in the RG if their AH was confirmed by examination in Department of Orthodontics, Eye Hospital of Hebei, were between 4 and 12 years old, snored or engaged in open mouth breathing, and their detailed case data were available. Children were excluded if they had a history of chronic rhinitis, turbinate hypertrophy, temporomandibular joint, or craniofacial trauma; received ear, nose, or throat surgery, or craniomaxillofacial orthodontic treatment; and if they had congenital developmental disorders. The inclusion and exclusion criteria were the same for the CG, the only difference being children enrolled in the CG were not confirmed to have $\mathrm{AH}$.

\section{Study methods}

\section{Height measurement}

During admission to hospital, we measured the height of each child in the two groups using an automatic height detector.

\section{Growth factor detection}

A sample of fasting venous blood $(2 \mathrm{~mL})$ was taken from each child and placed in a coagulation-promoting tube, followed by $10 \mathrm{~min}$ centrifugation $\left(1,505 \times \mathrm{g}, 4^{\circ} \mathrm{C}\right)$ to obtain serum after $30 \mathrm{~min}$ still standing at indoor temperature, and IGF1 and IGFBP-3 in the serum were quantified using the electrochemical luminescence method.

\section{X-ray examination}

A lateral cranial image was taken from each child at a voltage of $86 \mathrm{kV}$, current of $16 \mathrm{~mA}$, and exposure time of $16 \mathrm{~s}$ (Figure 1). In the image, the following items were then measured: the vertical length of the tangent line from the lowest end of the lower part of the adenoid to the cranial lateral side of 

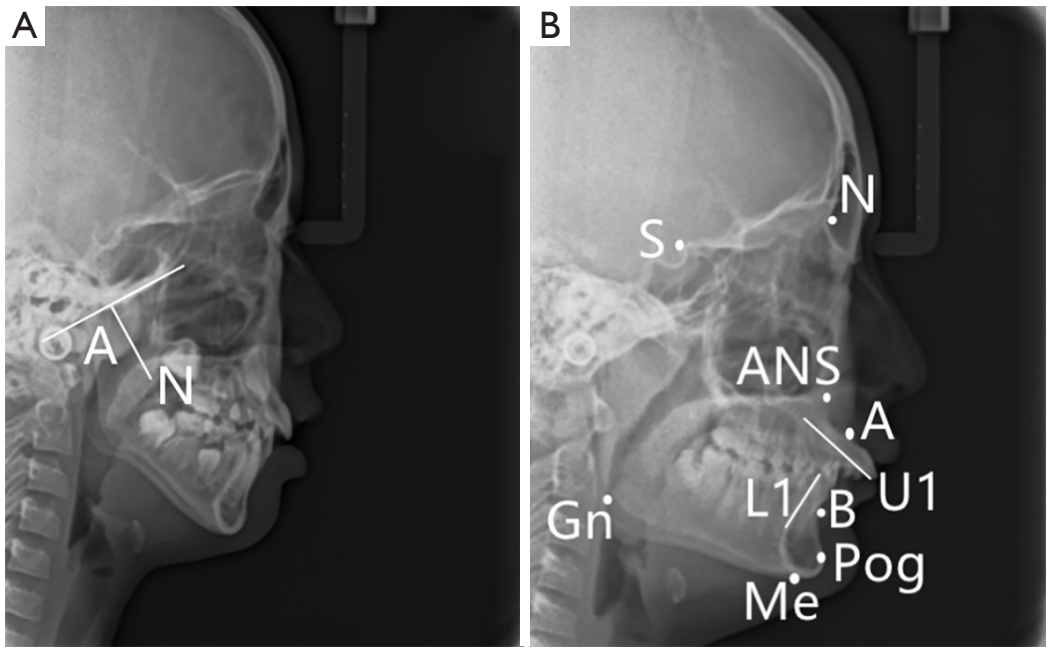

Figure 1 X-ray results. (A) Adenoid index. A: thickness of adenoid; N: nasopharynx cavity width. (B) Lateral cranial markings. N: the most concave point of the bone between the anterior nasal spine and the edge of the upper alveolar; S: the most concave point of the bone between the anterior nasal spine and the edge of the upper alveolar; A: the most concave point of the bone between the anterior nasal spine and the edge of the upper alveolar; B: the most concave point of the bone between the anterior nasal spine and the edge of the upper alveolar; Me: the lowest point of the chin; Gn: the midpoint between the pre-chin point and the sub-chin point; L1: the midpoint between the pre-mental point and the submental point; U1: the midpoint between the pre-mental point and the submental point; Pog: the midpoint between the pre-chin point and the sub-chin point; ANS: the tip of the anterior nasal spine is used as one of the two landmark points to determine the palatal plane.

the basilar clivus (A), nasopharynx cavity width $(\mathrm{N})$, distance between the nasopharynx apex (PNS) and R (point located at the intersection of the posterior pharyngeal wall and PNS-Hor line) (PNS-R), distance between the PNS and UPW (point located at the intersection of the posterior pharyngeal wall and PNS-Ba line) (PNS-UPW), distance between the SPP (point of intersection of the line from the soft palate center perpendicular to the posterior pharyngeal wall and posterior margin of the soft palate) and SPPW (point of intersection of the line from the soft palate center perpendicular to the posterior pharyngeal wall and posterior pharyngeal wall) (SPP-SPPW), distance between U (tip of soft palate) and MPW (foot point at the posterior pharyngeal wall of perpendicular line from point $\mathrm{U}$ ) (U-MPW), the angle between the subspinale and sella at nasion (representing the position of the maxilla in relation to the cranium) (SNA angle), the angle between the supraemental and sella at nasion (representing the position of the mandible in relation to the cranium) (SNB angle), and the angle between the subspinale and supraemental at nasion (representing the relationship of maxilla and mandible in relation to the cranium) (ANB). In addition, Dolphin software was used to analyze the angles between the plane of the anterior skull base and the facial plane (NPog-SN), the former and the mandibular plane (GoGn-SN), the upper central incisor long axis and the NA plane (U1-NA), the upper central incisor long axis and NB plane (L1-NB), and the upper central incisor long axis and mandibular plane (IMPA).

\section{Electronic nasopharyngoscope examination}

A Japanese Olympus ENF-VT2 electronic nasopharyngoscope was adopted for examination. The child was let to keep a sitting position, with the lower jaw slightly lift and the hands, feet and head positions all fixed, and then required to receive spray anesthesia for bilateral nasal cavity twice, at an interval of 3-5 min. The nasopharyngoscope was inserted into the nasal cavity through nostril to check nasal mucosa, and then the nasopharyngoscope was let to reach the nasopharyngeal cavity when nasal septum, chronic rhinitis, abnormal shape of turbinate can be ruled out. The child was instructed to breathe hard, followed by observation of the volume of adenoids in nostril. Synchronous images were collected, and transmitted to computer synchronously.

\section{Sleep quality evaluation}

The Pittsburgh Sleep Quality Index (PSQI) was used 
Table 1 Baseline data

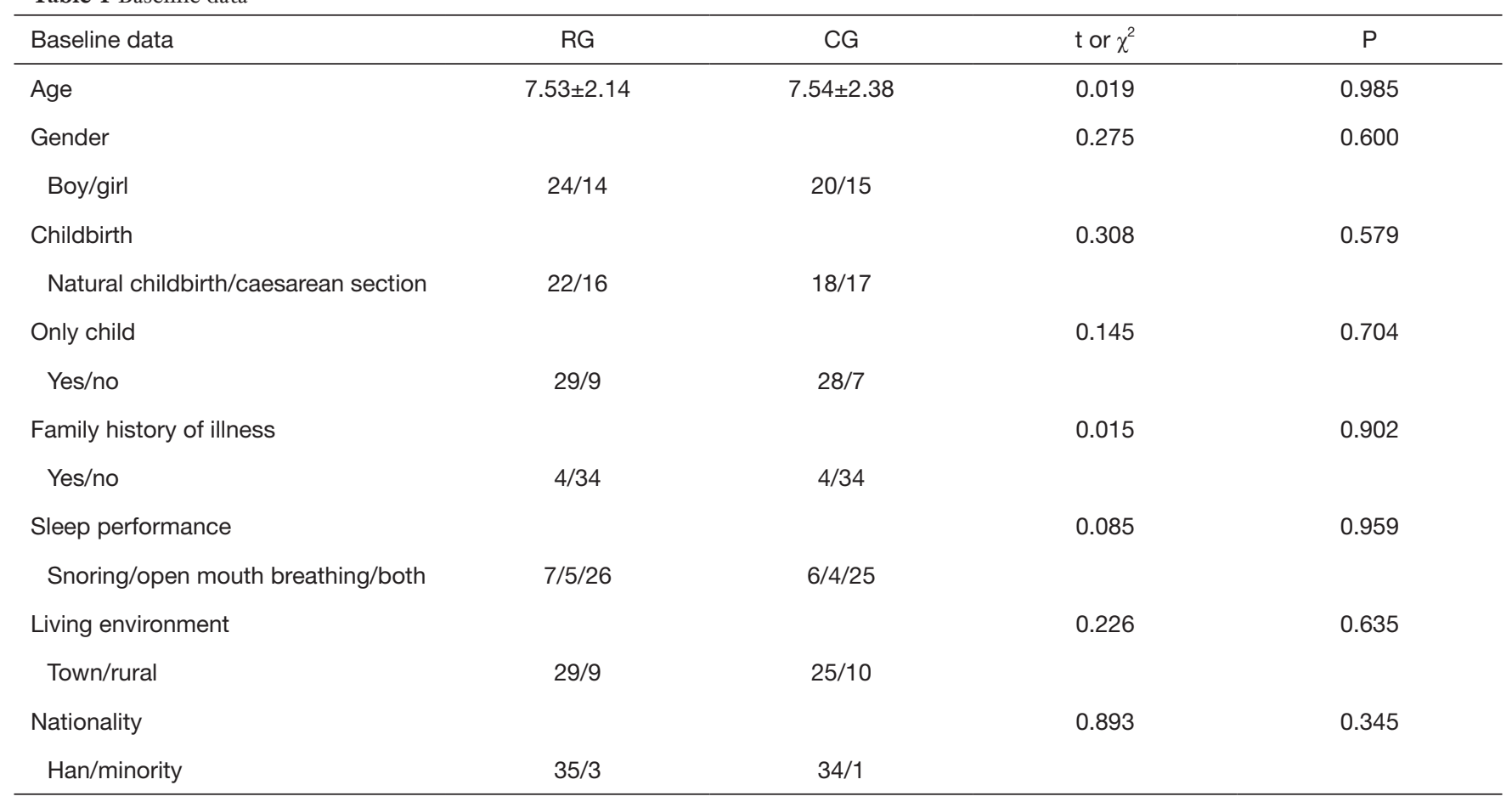

RG, research group; CG, control group.

to evaluate the sleep quality, efficiency, and time of the children in the two groups (12). The scale comprised selfassessment items and other assessment items which include seven modules, namely, sleep quality, time to fall asleep, sleep time, sleep efficiency, sleep disorder, hypnotic drugs, and daytime dysfunction.

With a total score of $0-21$ points, the scale indicates sleep disorder by a score $>7$ points, and a higher score indicates more serious sleep disorder.

\section{Outcome measures}

The outcomes of the two groups were determined using the height and growth factors [insulin-like growth factor-1 (IGF-1) and insulin-like growth factor binding protein-3 (IGFBP-3)], the measurement results of the sagittal diameter of the upper airway (A, N, PNS-P, PNSUPW, SPP-SPPW, and U-MPW), the relative indexes of malocclusion (NPog-SN, GoGn-SN, U1-NA, L1-NB, and IMPA), the hard tissue cephalometric indexes (SNA angle, SNB angle, and ANB angle), and sleep quality.

\section{Statistical analysis}

All data were processed using SPSS (version 25.0) (IBM
Corp., Armonk, NY, USA). Counting data (n/\%) were processed using a chi-square test. Measurement data $(\bar{x} \pm \mathrm{s})$ in normal distribution were analyzed by the independentsamples $t$-test, and those not in normal distribution by the Whitney $\mathrm{U}$ test. $\mathrm{P}<0.05$ denotes a remarkable difference.

\section{Results}

\section{Clinical baseline data}

The clinical baseline data (e.g., age and gender) was no notably different between the two groups $(\mathrm{P}>0.05)$. Under the electronic nasopharyngoscope, with the adenoid size occupying $50 \%$ of the posterior nostril as the threshold, there were 23 patients $(60.5 \%)$ with the adenoid occupying $\geq 50 \%$ of the posterior nostril and 15 patients $(39.5 \%$ with the adenoid occupying $<50 \%$ of the posterior nostril in the RG (Table 1).

\section{Comparison of height and growth factors}

According to the results, the height of the RG was lower than that of the CG $(\mathrm{P}<0.05)$, and the levels of IGF-1 $(186.88 \pm 22.86 \mathrm{ng} / \mathrm{mL})$ and IGFBP-3 $(5.42 \pm 0.89 \mu \mathrm{g} / \mathrm{mL})$ in 
A

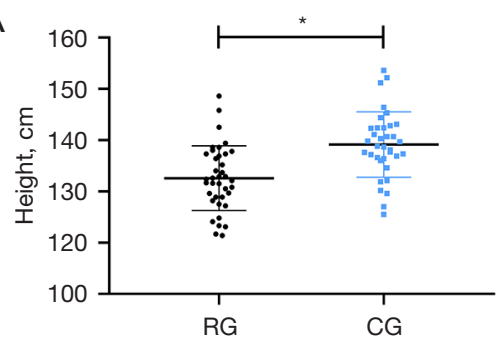

B

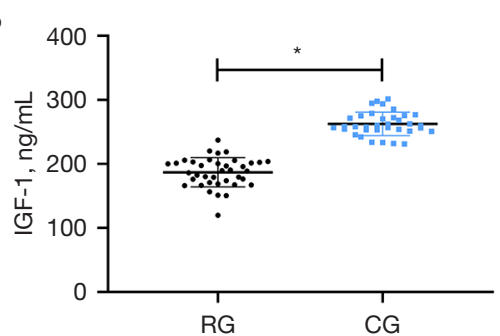

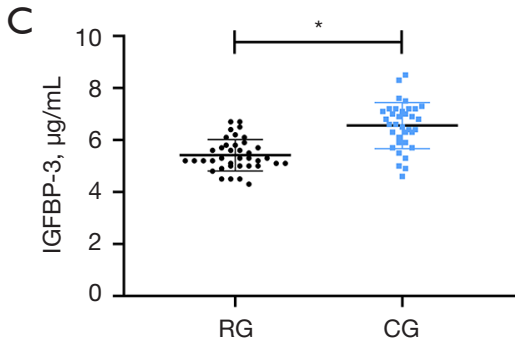

Figure 2 Comparison of height and growth factors. (A) Comparison of height. (B) Comparison of IGF-1. (C) Comparison of IGFBP-3. *, P<0.05. IGF-1, insulin-like growth factor-1; IGFBP-3, insulin-like growth factor binding protein-3; RG, research group; CG, control group.

A

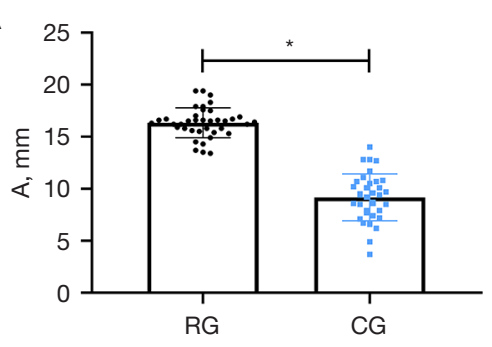

$\mathrm{D}$

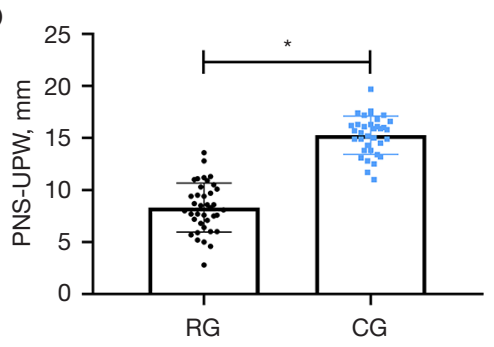

B

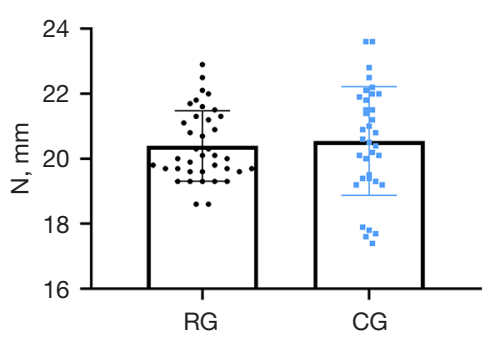

$\mathrm{E}$

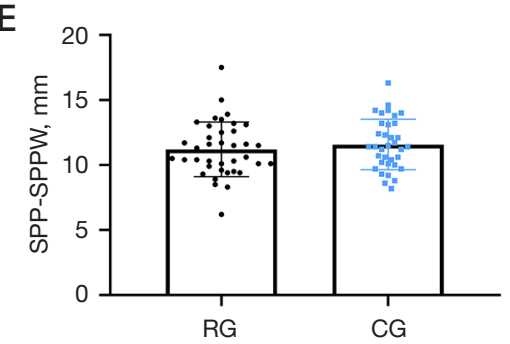

C

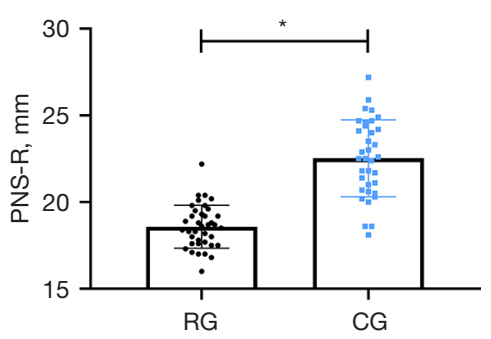

$\mathrm{F}$

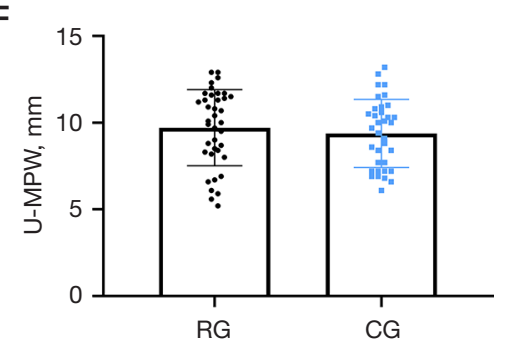

Figure 3 Measurement results of the sagittal diameter of the upper airway. (A) Comparison of A. (B) Comparison of N. (C) Comparison of PNS-R. (D) Comparison of PNS-UPW. (E) Comparison of SPP-SPPW. (F) Comparison of U-MPW. *, P<0.05. A: the vertical length of the tangent line from the lowest end of the lower part of the adenoid to the cranial lateral side of the basilar clivus; $\mathrm{N}$ : nasopharynx cavity width; R: point located at the intersection of the posterior pharyngeal wall and PNS-Hor line; PNS: nasopharynx apex; PNS-R: distance between the PNS and R; UPW: point located at the intersection of the posterior pharyngeal wall and PNS-Ba line; PNS-UPW: distance between the PNS and UPW. RG, research group; CG, control group.

the RG were also lower than those in the CG (both $\mathrm{P}<0.05)$ (Figure 2).

\section{Comparison of the sagittal diameter of the upper airway measurement results}

According to the measurement results, the two groups did not greatly differ in N, SPP-SPPW, and U-MPW (all $\mathrm{P}>0.05)$, but the RG showed higher A and lower PNS-R and PNS-UPW than the CG (both $\mathrm{P}<0.05$ ) (Figure 3).

\section{Comparison of relative indexes of malocclusion}

We found no notable difference between the two groups in NPog-SN, GoGn-SN, and IMPA (all P>0.05), but U1-NA and L1-NB in the RG were both higher than those in the $\mathrm{CG}(\mathrm{P}<0.05)$ (Figure 4).

\section{Hard tissue cephalometric indexes}

The angles of SNA and ANB in the RG were both lower 
A

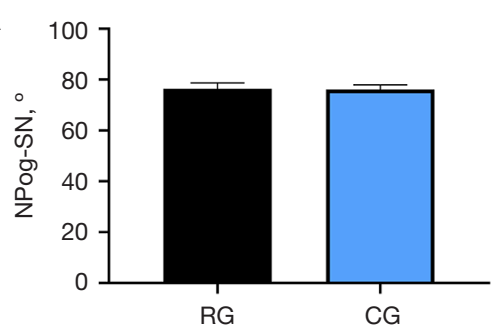

D

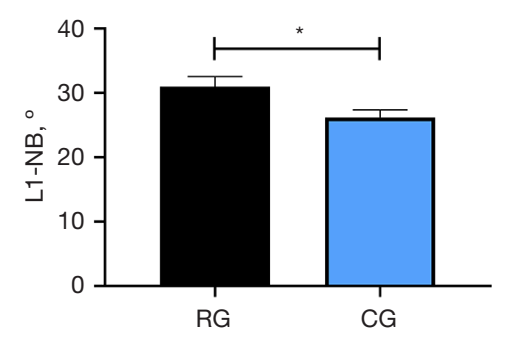

B

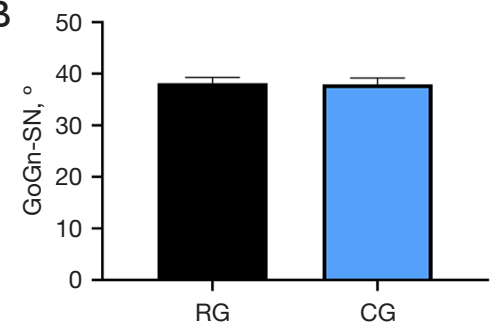

$\mathrm{E}$

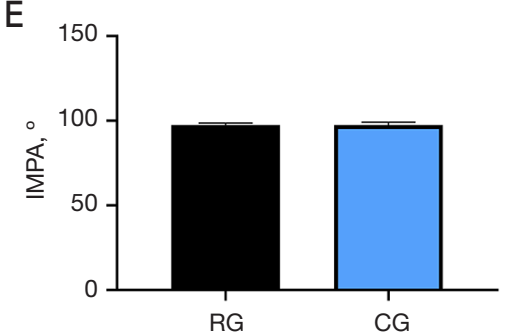

C

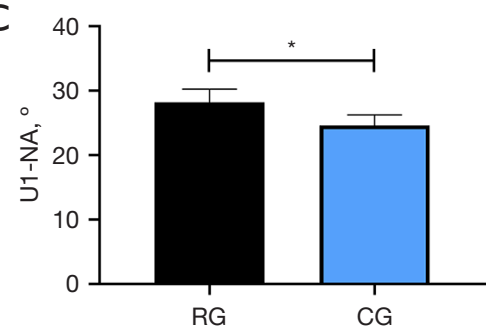

Figure 4 Comparison of the relative indexes of malocclusion. (A) Comparison of NPog-SN. (B) Comparison of GoGn-SN. (C) Comparison of U1-NA. (D) Comparison of L1-NB. (E) Comparison of IMPA. *, P<0.05. NPog-SN: the angles between the plane of the anterior skull base and the facial plane; GoGn-SN: the former and the mandibular plane; U1-NA: the upper central incisor long axis and the NA plane; L1-NB: the upper central incisor long axis and NB plane; IMPA: the upper central incisor long axis and mandibular plane. RG, research group; CG, control group.

A

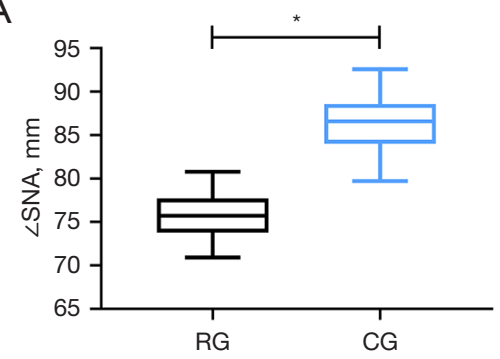

B

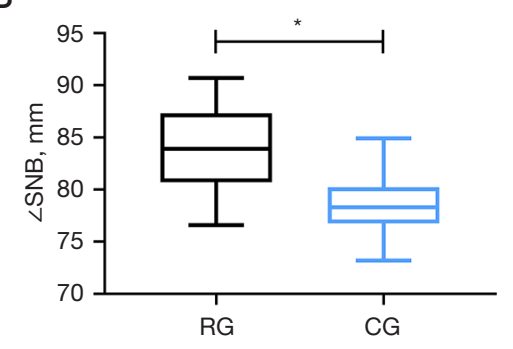

C

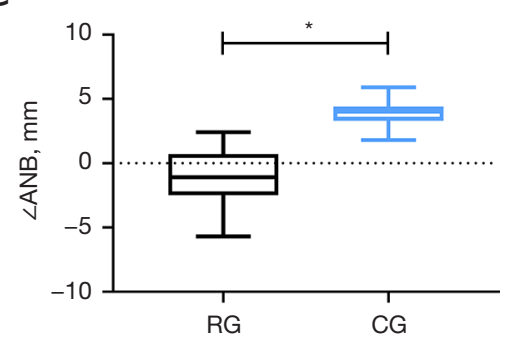

Figure 5 Comparison of hard tissue cephalometric indexes. (A) Comparison of SNA. (B) Comparison of SNB. (C) Comparison of ANB. * $\mathrm{P}<0.05$. SNA: the angle between the subspinale and sella at nasion (indicating the site of the maxilla in relation to the cranium); ANB: the angle between the subspinale and supraemental at nasion (indicating the association of maxilla and mandible in relation to the cranium); SNB: the angle between the supraemental and sella at nasion (indicating the site of the mandible in relation to the cranium). RG, research group; CG, control group.

than those in the CG $(\mathrm{P}<0.05)$, while the angle of SNB in the former was higher than that in the latter $(\mathrm{P}<0.05)$ (Figure 5).

\section{Comparison of sleep quality}

Following our sleep quality evaluation, we found that the time to fall asleep $(23.16 \pm 4.05 \mathrm{~min})$ and the PSQI score $(14.00 \pm 4.25$ points) of the RG were higher than those of the
CG (all $\mathrm{P}<0.05)$ (Figure 6).

\section{Discussion}

The adenoid is an organ of lymphoid tissue located at the top of the nasopharynx and posterior pharyngeal wall (13). Adenoids are in exuberant growth in children between 2 and 6 years old, and they gradually start to shrink in children after the age of 10 years (14). Therefore, AH usually occurs in 
A

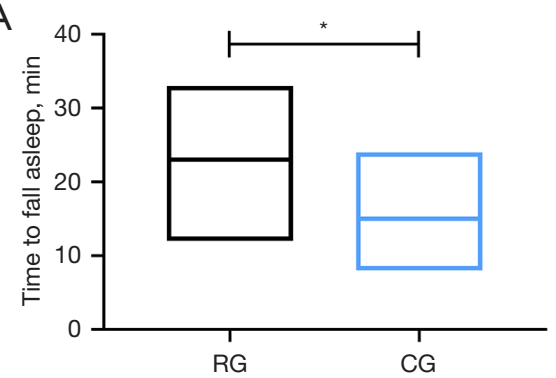

B

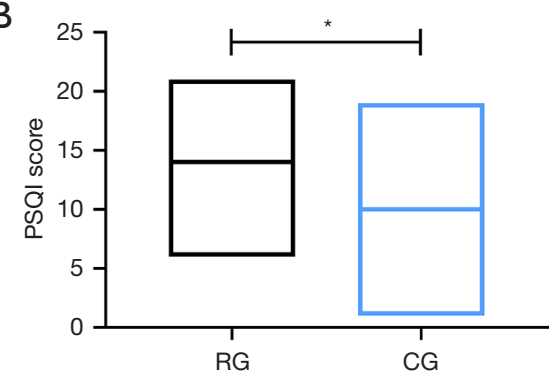

Figure 6 Comparison of sleep quality. (A) Comparison of time to fall asleep. (B) Comparison of PSQI score. * P<0.05. PSQI, Pittsburgh Sleep Quality Index; RG, research group; CG, control group.

children aged 2 to 6 years (15). The condition can give rise to nasal congestion and open mouth breathing, especially during sleep, and can even result in sleep apnea. For this reason, it is considered a particularly serious condition for children as they are in the most important stage of growth and development (16). Current clinical research on $\mathrm{AH}$ focuses on symptoms of oppression and obstruction. For instance, one study by Lou et al. (17) found a close relationship between $\mathrm{AH}$ and allergic rhinitis in children, while another study by Gomaa et al. revealed that $\mathrm{AH}$ can give rise to thickening of the laryngeal mucosa (18). There are also studies on AH-induced changes of the upper airway (19), but they are highly limited, and have not evaluated and analyzed the upper airway structure of children in detail. In response to increasingly high incidences of $\mathrm{AH}$, understanding its pathological mechanism and potential influence as soon as possible is the key to preventing and treating $\mathrm{AH}$ in the future. This study determined to evaluate the impact of $\mathrm{AH}$ on the upper airway and craniomaxillofacial region, and thus provide a reliable reference for future clinical and follow-up research.

In this study, we first measured the height of the two groups and determined their IGF-1 and IGFBP-3. As a result, we found lower IGF-1 and IGFBP-3 in the RG than those in the CG, indicating that children with AH have a notably slower growth and development. As we know, a child's growth and development is regulated and influenced by many factors, with hormones released by the hypothalamus playing one of the most crucial parts (20). IGF-1 is one of the active factors secreted by hypothalamus, which has the function of transmitting growth hormones and promoting growth (21). IGFBP-3 is the specific binding protein of IGF-1, which can promote the bone activation of IGF-1 and accelerate bone development (22). Moreover, one study has revealed that a child's ability to secrete growth hormones during nighttime sleep is much stronger than that during daytime (23). This also speaks to the inhibition of growth and development in the RG, who demonstrated that children with $\mathrm{AH}$ slept poorly at night, and that as a result their body could not enter a deep-sleep state to stimulate the hypothalamus and accelerate the secretion of the growth hormone. This result has also been verified in our PSQIbased investigation results about the sleep quality of the two groups, and the results of previous research are consistent with our study $(24,25)$. To understand the influence of $\mathrm{AH}$ on the upper airway, we evaluated the upper airway and craniomaxillofacial region of the two groups by $\mathrm{X}$-ray. The results revealed an increase in A and decreases in PNS-P and PNS-UPW in the RG, which suggested that the upper respiratory tract of children with $\mathrm{AH}$ obviously narrowed as a result of $\mathrm{AH}$, and that this was also the main reason for children to breathe with their mouths open during sleep. We speculated that the narrowing of the upper airway had changed the respiratory function and mode of the children, resulting in a certain degree of changes in the oral muscles, as well as damage in the balance between the oral muscles and the jaws, which eventually gave rise to abnormal growth of the jaws and teeth. In addition, because of the stenosis of the upper airway, the air pressure during breathing may cause the soft tissue of the upper airway of children to collapse, causing excessive swelling of the soft palate, tongue root, and pharynx, before finally forming an obstruction. As everyone knows, the wrong way of breathing exerts a heavily negative impact on the growth and physical health of maxillofacial region. According to one study (26), the growth of maxillofacial region is a response to functional needs, and local and regional factors heavily impact maxillofacial growth and development, while the growth of cartilage and bone is a compensatory response to functional matrix (26). 
Breathing pattern determines the shape of maxillofacial, craniofacial and facial muscles to a large extent, and its change can bring about the change of jaw posture. When the original balance of perioral muscle strength is broken, after the adjustment of neuromuscular, teeth and jaw gradually adapt to the wrong balance state, resulting in other abnormal movements and growth (27). In addition, long-term mouth breathing promotes the head and neck of the child to gradually extend forward, resulting in an increase in the anteversion angle of the craniocervical angle (28). An anteversion angle greater than $5^{\circ}$ is also one of the major reasons for deformities to develop in the craniomaxillofacial region, which is also a major reason for correcting the head posture and angle of patients in clinical orthodontic treatment (29). According to the comparison results of craniomaxillofacial growth between the two groups in our study, the RG showed larger angles of U1-NA, L1-NB, and SNB, and smaller angles of SNA and ANB, which verified our above speculation. From this, we can draw a preliminary conclusion that $\mathrm{AH}$ causes craniomaxillofacial deformity by causing upper airway stenosis. In addition, tonsil hypertrophy, as another common tissue lesion in children, is different from $\mathrm{AH}$ in that tonsil hypertrophy does not change the facial structure of children, and its clinical manifestations are mainly tinnitus, deafness, nasal congestion, runny nose, breathing with open mouth, coughing and spitting, and dysphagia (30). However, AH may give rise to inflammatory lesions of tonsil, which will trigger the development of tonsil hypertrophy. Therefore, more attention should be paid to the treatment of $\mathrm{AH}$ patients in clinic, which requires not only timely correction and intervention of maxillofacial deformities caused by $\mathrm{AH}$, but also attention to the occurrence of tonsil lesions.

It is also important to mention the limitations of this study, including the fact only 73 patients in total were enrolled. This means the statistical calculation of some test results may not be representative. In addition, the baseline characteristics of the participants were relatively similar, so we were unable to see how ethnic and growth environment differences affect the test results. For instance, children living in high altitude areas such as Tibet and Yunnan province have adapted to the respiratory compensation under hypoxia since childhood, so their respiratory changes triggered by $\mathrm{AH}$ are probably not as significant as those in other areas. Moreover, the comparison is based on the examination results of the two groups at their admission, so it is impossible to evaluate the differences in various indicators of patients after treatment. In addition, this study is based on the analysis results of X-ray. Cone-beam CT is an examination method extensively adopted in maxillofacial examination over the recent years, which can provide submillimeter resolution images by three-dimensional image reconstruction based on three-dimensional plan, and can deliver a higher resolution than $\mathrm{X}$-ray. However, the cone beam CT has not been extensively adopted in Department of Orthodontics, Beijing Stomatological Hospital, Capital Medical University. We will supplement the correlation of AH with cone beam CT examination results as soon as possible. The above are the directions worth improving in subsequent research. In the future, we will conduct a longer follow-up investigation on the participants of this study, and a more comprehensive experimental analysis on the impact of $\mathrm{AH}$ on multiple respiratory organs such as the upper airway, throat, and nasal cavity to obtain more accurate results for clinical reference.

\section{Conclusions}

$\mathrm{AH}$ can change the breathing mode and function of children by giving rise to upper airway stenosis. From this, deformities of the craniomaxillofacial region and oral cavity can develop, disrupting the normal growth and development of a child.

\section{Acknowledgments}

Funding: None.

\section{Footnote}

Reporting Checklist: The authors have completed the STROBE reporting checklist. Available at https://dx.doi. org/10.21037/tp-21-437

Data Sharing Statement: Available at https://dx.doi. org/10.21037/tp-21-437

Conflicts of Interest: All authors have completed the ICMJE uniform disclosure form (available at https://dx.doi. org/10.21037/tp-21-437). The authors have no conflicts of interest to declare.

Ethical Statement: The authors are accountable for all aspects of the work in ensuring that questions related to the accuracy or integrity of any part of the work are appropriately investigated and resolved. The study was 
conducted in accordance with the Declaration of Helsinki (as revised in 2013). This experiment was carried out with permission from the Ethics Committee of Beijing Stomatological Hospital, Capital Medical University, and informed consent forms were signed by the guardians of all enrolled children.

Open Access Statement: This is an Open Access article distributed in accordance with the Creative Commons Attribution-NonCommercial-NoDerivs 4.0 International License (CC BY-NC-ND 4.0), which permits the noncommercial replication and distribution of the article with the strict proviso that no changes or edits are made and the original work is properly cited (including links to both the formal publication through the relevant DOI and the license). See: https://creativecommons.org/licenses/by-nc-nd/4.0/.

\section{References}

1. Pereira L, Monyror J, Almeida FT, et al. Prevalence of adenoid hypertrophy: a systematic review and metaanalysis. Sleep Med Rev 2018;38:101-12.

2. Cao $\mathrm{C}, \mathrm{Xu} \mathrm{Y}$. The correlation between adenoid hypertrophy and allergic rhinitis. Lin Chung Er Bi Yan Hou Tou Jing Wai Ke Za Zhi 2019;33:381-4.

3. Durgut O, Dikici O. The effect of adenoid hypertrophy on hearing thresholds in children with otitis media with effusion. Int J Pediatr Otorhinolaryngol 2019;124:116-9.

4. Abdel-Aziz M, El-Fouly M, Elmagd EAA, et al. Adenoid hypertrophy causing obstructive sleep apnea in children after pharyngeal flap surgery. Eur Arch Otorhinolaryngol 2019;276:3413-7.

5. Sikorska-Żuk M, Bochnia M. Halitosis in children with adenoid hypertrophy. J Breath Res 2018;12:026011.

6. Sakarya EU, Bayar Muluk N, Sakalar EG, et al. Use of intranasal corticosteroids in adenotonsillar hypertrophy. J Laryngol Otol 2017;131:384-90.

7. Soldatova L, Otero HJ, Saul DA, et al. Lateral neck radiography in preoperative evaluation of adenoid hypertrophy. Ann Otol Rhinol Laryngol 2020;129:482-8.

8. Baldassari CM, Choi S. Assessing adenoid hypertrophy in children: X-ray or nasal endoscopy? Laryngoscope 2014;124:1509-10.

9. Chen W, Cao W, Shen J, et al. The efficacy of OM85$\mathrm{BV}$ in the treatment of recurrent upper respiratory tract infection with adenoid hypertrophy and the preliminary exploration of potential therapeutic mechanism. Lin Chung Er Bi Yan Hou Tou Jing Wai Ke Za Zhi
2020;34:499-504.

10. Cakabay T, Üstün Bezgin S, Bayramoglu SE, et al. Evaluation of choroidal thickness in children with adenoid hypertrophy. Eur Arch Otorhinolaryngol 2018;275:439-42.

11. Mollayeva T, Thurairajah P, Burton K, et al. The Pittsburgh sleep quality index as a screening tool for sleep dysfunction in clinical and non-clinical samples: a systematic review and meta-analysis. Sleep Med Rev 2016;25:52-73.

12. Holzki J, Brown KA, Carroll RG, et al. The anatomy of the pediatric airway: Has our knowledge changed in 120 years? A review of historic and recent investigations of the anatomy of the pediatric larynx. Paediatr Anaesth 2018;28:13-22.

13. Brodsky L. Modern assessment of tonsils and adenoids. Pediatr Clin North Am 1989;36:1551-69.

14. Marseglia GL, Caimmi D, Pagella F, et al. Adenoids during childhood: the facts. Int J Immunopathol Pharmacol 2011;24:1-5.

15. Brambilla I, Pusateri A, Pagella F, et al. Adenoids in children: advances in immunology, diagnosis, and surgery. Clin Anat 2014;27:346-52.

16. Pagella F, Colombo A, Gatti O, et al. Rhinosinusitis and otitis media: the link with adenoids. Int J Immunopathol Pharmacol 2010;23:38-40.

17. Lou Z. Adenoid hypertrophy in children and allergic rhinitis. Eur Arch Otorhinolaryngol 2018;275:831-2.

18. Gomaa MA, Mohammed HM, Abdalla AA, et al. Effect of adenoid hypertrophy on the voice and laryngeal mucosa in children. Int J Pediatr Otorhinolaryngol 2013;77:1936-9.

19. Yıldırım U, Kemal Ö, Kavaz E, et al. A rare cause of acute severe upper airway obstruction that required endotracheal intubation: adenoid hypertrophy. Turk Pediatri Ars 2020;55:199-202.

20. Ogawa S, Liu X, Shepherd BS, et al. Ghrelin stimulates growth hormone release from the pituitary via hypothalamic growth hormone-releasing hormone neurons in the cichlid, Oreochromis niloticus. Cell Tissue Res 2018;374:349-65.

21. Halmos T, Suba I. The physiological role of growth hormone and insulin-like growth factors. Orv Hetil 2019;160:1774-83.

22. Hine C, Kim HJ, Zhu Y, et al. Hypothalamic-pituitary axis regulates hydrogen sulfide production. Cell Metab 2017;25:1320-33.e5.

23. Sadagurski M, Landeryou T, Cady G, et al. Growth hormone modulates hypothalamic inflammation in long- 
lived pituitary dwarf mice. Aging Cell 2015;14:1045-54.

24. Kimbell JS, Basu S, Garcia GJM, et al. Upper airway reconstruction using long-range optical coherence tomography: effects of airway curvature on airflow resistance. Lasers Surg Med 2019;51:150-60.

25. Naiboglu B, Deveci S, Duman D, et al. Effect of upper airway obstruction on pulmonary arterial pressure in children. Int J Pediatr Otorhinolaryngol 2008;72:1425-9.

26. Yoon TL, Cynn HS, Choi SA, et al. Effect of the craniocervical brace on craniocervical angle, thoracic kyphosis angle, and trunk extensor muscle activity during typing in subjects with forward head posture. Work 2016;55:163-9.

27. Kim DH, Kim SY. Comparison of immediate effects of sling- based manual therapy on specific spine levels in subjects with neck pain and forward head posture: a randomized clinical trial. Disabil Rehabil 2020;42:2735-42.

28. Yamaguchi H, Tada S, Nakanishi Y, et al. Association between mouth breathing and atopic dermatitis in Japanese children 2-6 years old: a population-based cross-sectional study. PLoS One 2015;10:e0125916.

29. Baxter DJ, Shroff MM. Developmental maxillofacial anomalies. Semin Ultrasound CT MR 2011;32:555-68.

30. Tang JA, Friedman M. Incidence of lingual tonsil hypertrophy in adults with and without obstructive sleep apnea. Otolaryngol Head Neck Surg 2018;158:391-4.

(English Language Editor: J. Geotz)

Cite this article as: Wang H, Qiao X, Qi S, Zhang X, Li S. Effect of adenoid hypertrophy on the upper airway and craniomaxillofacial region. Transl Pediatr 2021;10(10):25632572. doi: $10.21037 /$ tp-21-437 